\title{
A LÍNGUA BRASILEIRA DE SINAIS NAS UNIVERSIDADES PÚBLICAS DA REGIÃO CENTRO OESTE: DILEMAS, CONQUISTAS E HORIZONTES
}

\author{
Lázara Cristina da Silva* \\ Marilda Moraes Garcia Bruno** \\ Dulcéria Tartuci ${ }^{* * *}$
}

\begin{abstract}
RESUMO
O texto visa apresentar as condições em que ocorreram a inserção da Libras nas instituições públicas da região Centro-Oeste brasileira, a sua operacionalização, considerando que em 2015 se completa uma década da aprovação do Decreto $\mathrm{n}$. $5.626 / 05$, que regulamenta a inserção da Libras nos cursos de Licenciatura. Destacase que as primeiras iniciativas de implantação da disciplina Libras e sua oferta têm sido realizadas a partir do esforço de pessoas e unidades acadêmicas/departamentos envolvidos com a educação de surdos e o ensino de Libras. As modificações neste processo só vieram a ocorrer com o Programa Viver Sem Limites do governo federal, que procurou induzir a criação de cursos de formação de professores para os processos de escolarização da população surda a partir de 2013. Para além da destinação de vagas de docentes, existem outras demandas mais profundas a precisam serem perseguidas, relacionadas às mudanças de atitudes e posturas dos profissionais.
\end{abstract}

Palavras - chave: Libras. Licenciaturas. Políticas públicas educacionais.

* Doutora em Educação pela Universidade Federal de Uberlândia (UFU). Professora e coordenadora da linha de pesquisa Estado, Política e Gestão da Educação do Programa de Pós-graduação em Educação da UFU. E-mail: lazara@ufu.br

** Doutora em Ensino da Educação Brasileira pela Universidade Estadual Paulista - Júlio de Mesquita Filho (UNESP). Professora Associada da Universidade Federal da Grande Dourados (UFGD). Docente do Programa de Pós Graduação em Educação da Faculdade de Educação. Pesquisadora da Linha Educação e Diversidade. Líder do GEPEI - Grupo de Estudos e Pesquisa em Educação Inclusiva. E-mail: MarildaBruno@ufgd.edu.br

${ }^{* * *}$ Doutora em Educação pela Universidade Metodista de Piracicaba (UNIMEP). Professora do Programa de Pós-Graduação em Educação (Linha de Pesquisa: Práticas Educativas, Políticas Educacionais e Inclusão) e do Curso de Pedagogia do Departamento de Educação da Universidade Federal de Goiás - campus Catalão. Coordena o Subprojeto do Programa Institucional de Bolsas de Iniciação à Docência do Curso de Pedagogia - campus Catalão-UFG. Líder do Núcleo de Estudos e Pesquisa em Práticas Educativas e Inclusão (NEPPEIn) e integrante do Banco de Avaliadores do Sistema Nacional de Avaliação da Educação Superior - BASis/INEP (MEC). E-mail: dutartuci@brturbo.com.br 


\begin{abstract}
The presentation aims to present the conditions under which occurred the inclusion of the Brazilian Sign Language (Libras) in public institutions in the Midwest Brazilian region, its operation, considering that 2015 was a decade full approval of Decree 5.626/05, which regulates the insertion of Libras undergraduate courses. It is noteworthy that the first steps of implementation of discipline Libras and your offer, has been accomplished from the efforts of people and academic units / departments concerned with the education of the deaf and the teaching of Libras. The changes in this process only occurred with the Living Without Limits Program of the federal government, which pursued to induce the creation of training courses for teachers of the deaf schooling processes from 2013. There are other deeper demands that need to be pursued, such as those related to changes in attitudes and professionals' postures .
\end{abstract}

Keywords: Libras. Degrees. Teaching Libras.

ALíngua de Sinais é reconhecida como modalidade linguística natural utilizada pelas pessoas surdas de diferentes países. Este processo de reconhecimento foi resultado da luta organizada por grupos de pessoas surdas ${ }^{1} \mathrm{em}$ seus países de origem que, por meio de movimentos políticos, buscaram garantir a sua inserção como instrumento legal de comunicação, aprendizagem e desenvolvimento.

Este artigo tem como objetivo refletir sobre as condições em que ocorreram a inserção da Línga Brasileira de Sinais - Libras nas principais instituições públicas da região Centro-Oeste brasileira, bem como mapear a sua operacionalização, considerando que, em 2015, se completa uma década da aprovação do Decreto n. 5.626/05, que regulamenta a sua inserção nos cursos de Licenciatura.

Neste sentido, será apresentada uma breve reflexão sobre as condições legais para a implantação da Libras como componente curricular nos cursos de Licenciatura, e suas implicações na organização das IES públicas federais da região selecionada. Para tanto, serão mapeados os processos institucionais desenvolvidos no tocante à alocação da disciplina, carga horária, ementa e contratação de docentes para sua realização, para, em seguida, pensarmos alguns horizontes para a promoção de condições ampliadas na formação docente, com foco na atuação em processos de escolarização de estudantes

1 Neste texto, a utilização da palavra surdo(a) refere-se ao grupo de pessoas surdas que possuem vínculo identitários com a língua de sinais e encontra-se inserido nos movimentos de lutas sociais organizados da categoria e, surdo(a), quando trata-se de pessoas surdas em geral, não abordando diretamente tal aspecto. 
surdos na rede regular de ensino brasileira.

\subsection{A Libras: perspectivas legais e desejos dos grupos organizados de pessoas Surdas}

Desde o início da década de 1990, se evidencia a grande preocupação da Federação Nacional de Educação e Integração dos Surdos (Feneis) com a oficialização da Língua Brasileira de Sinais em todos os estados brasileiros. Tal situação demarca a existência de um movimento político/social organizado, buscando demonstrar as autoridades governamentais a necessidade e a relevância do reconhecimento da Língua de Sinais para a ampliação das condições de inclusão social e educacional das pessoas Surdas, bem como a necessidade da criação e regulamentação da função de Intérprete para o desenvolvimento educacional, cultural e social desta parcela da população brasileira.

As modificações legais resultantes deste processo começam a se desenhar em 1991, quando, em âmbito estadual, ocorre o reconhecimento legal da Libras enquanto língua natural das pessoas surdas em alguns entes federados, sendo pioneiros neste processo de reconhecimento da Libras os Estados de Minas Gerais, Maranhão, Goiás e Mato Grosso do Sul.

Em Minas Gerais, o reconhecimento veio por meio da Lei Estadual n. 10.379 , de 10 de janeiro de 1991, por meio da qual "fica reconhecida oficialmente, pelo Estado de Minas Gerais, a linguagem gestual codificada na Língua Brasileira de Sinais - Libras - e outros recursos de expressão a ela associados, como meio de comunicação objetiva e de uso corrente" (MINAS GERAIS, 1991, Artigo $1^{\circ}$ ).

Ainda nesta lei, no Artigo $2^{\circ}$, determina-se que as repartições públicas, que trabalham com atendimento externo à população do estado, deverão possuir profissionais intérpretes de Libras, para garantir a acessibilidade aos cidadãos mineiros surdos.

No Artigo $3^{\circ}$, determina-se que:

fica incluída no currículo da rede pública estadual de ensino estendendo-se aos cursos de magistério, formação superior nas áreas das ciências humanas, médicas e educacionais, e às instituições que atendem ao aluno portador de deficiência auditiva, a Língua Brasileira de Sinais (MINAS GERAIS, 1991). 
Esta Lei foi alterada pela Lei n. 20.828 de agosto de 2013, na qual se acrescenta o Artigo $2^{\circ}$ A: "os Poderes do Estado, o Ministério Público e o Tribunal de Contas assegurarão o uso e a difusão da Libras nas produções audiovisuais realizadas por seus órgãos e entidades."

Esta modificação pode parecer irrisória, no entanto, não o é, pois na prática amplia as condições de acesso desta população às informações legais e ações desenvolvidas no estado, criando de fato possibilidades reais para o exercício da cidadania.

Por conseguinte, no campo legal, o Estado de Minas Gerais, mais uma vez, apresenta-se como pioneiro na definição de ações inovadoras no sistema educacional estadual; entretanto, mais de duas décadas após esta determinação, ainda é possível notar, em diferentes regiões do estado, dificuldades para atender à referida lei.

Em seguida, os Estados de Maranhão e Goiás reconheceram a Libras, em 1993, como língua de comunicação de sua população, mesmo ano em que o Mato Grosso do Sul também o fez no Município de Campo Grande. O reconhecimento para todo o Estado ocorreu em 1996. Considerando o recorte deste artigo, apresentar-se-á apenas as questões relacionadas aos estados da Região Centro-Oeste. A exceção para o estado de Minas Gerais ocorreu porque os dados do estudo envolveram a Universidade Federal de Uberlândia que, segundo organização da Coordenação de Aperfeiçoamento de Pessoal de Nível Superior (CAPES), as instituições do Triângulo Mineiro fazem parte da Região Centro-Oeste. Destaca-se aqui, que a Libras foi oficializada em Uberlândia em dezembro de 2000, pela Lei Municipal n. 7.762, dez anos após sua oficialização no Estado.

Em Goiás, a Libras foi oficializada pela Lei n. 12.081 de agosto de 1993, que, no seu Artigo $2^{\circ}$, define a responsabilidade do Estado em qualificar os profissionais do seu quadro de servidores para garantir a acessibilidade à população surda do Estado. A seguir, no Artigo $3^{\circ}$, como na Lei Mineira, define a inserção da Libras no currículo da rede pública estadual de ensino em geral.

A Lei Estadual n. 1.693 de 12 de setembro de 1996 reconhece a Libras no Estado de Mato Grosso do Sul. A Resolução n. 31 de 3 de maio de 2000, da Secretaria Municipal de Educação de Campo Grande, trata das normas e funcionamento da Educação Especial nas escolas da rede municipal; compõe a equipe pedagógica que atuará nas escolas (os professores das classes do ensino regular, os especialistas em educação, os professores das salas de recursos e/ 
ou de enriquecimento curricular, os professores itinerantes e os intérpretes de língua brasileira de sinais) e define os serviços de Apoio Educacional a serem oferecidos nas escolas. Em 2002, o Estado publica a Lei Estadual n. 2.469, que "dispõe sobre a utilização de recursos visuais destinados aos portadores de deficiência auditiva na veiculação de propaganda oficial".

Quatro anos depois, com a Lei Estadual n. 7.831 de 13 de dezembro de 2002, o Estado de Mato Grosso do Sul também fez o reconhecimento oficial da Libras, como meio de comunicação objetiva e de uso corrente da comunidade surda e a Lei Estadual n. 7.835, no mesmo ano, dispõe sobre a sua obrigatoriedade nas escolas da rede pública do estado. Apesar de, em âmbito estadual, a Libras ser reconhecida apenas em 2002, ano da sua oficialização nacionalmente, o Município de Campo Grande, desde 1993, já havia reconhecido a Libras pela Lei Municipal n. 2.997 de 10 de novembro de 1993.

No Distrito Federal, o reconhecimento da Libras ocorre juntamente com a publicação da Lei Federal n. 10.436/02. Entretanto, desde 1998, já existiam ações instituindo a sua obrigatoriedade em peças publicitárias para veiculação em emissoras de televisão, pela Lei Distrito Federal n. 2.089 de 29 de setembro de 1998. Em 1999, por meio da Lei Distrito Federal n. 2.272 , se estabelece a prestação de serviço suplementar de telefonia para as pessoas surdas e, em 2000, pela Lei Distrito Federal n. 2.532, se determina a qualificação de servidores públicos do Distrito Federal para o uso da Libras.

A oficialização da Libras abre as instituições públicas para novas demandas, entre elas a inserção do ensino da Libras nos cursos de formação de professores e licenciaturas. Nesse sentido, a Lei n. 10.436/2002, ao dispor sobre a Libras, apresenta em seu Artigo $4^{\circ}$ a exigência que

O sistema educacional federal e os sistemas educacionais estaduais, municipais e do Distrito Federal devem garantir a inclusão nos cursos de formação de Educação Especial, de Fonoaudiologia e de Magistério, em seus níveis médio e superior, do ensino da Língua Brasileira de Sinais - Libras, como parte integrante dos Parâmetros Curriculares Nacionais - PCNs, conforme legislação vigente (BRASIL, 2002).

Condição que é regulamentada pelo Decreto n. 5.626/2005, que, entre várias questões, dedica o Capítulo II para tratar "Da inclusão da Libras como Disciplina Curricular": 
Art. $3^{\circ} \mathrm{A}$ Libras deve ser inserida como disciplina curricular obrigatória nos cursos de formação de professores para o exercício do magistério, em nível médio e superior, e nos cursos de Fonoaudiologia, de instituições de ensino, públicas e privadas, do sistema federal de ensino e dos sistemas de ensino dos Estados, do Distrito Federal e dos Municípios.

$\S 1$ o Todos os cursos de licenciatura, nas diferentes áreas do conhecimento, o curso normal de nível médio, o curso normal superior, o curso de Pedagogia e o curso de Educação Especial são considerados cursos de formação de professores e profissionais da educação para o exercício do magistério.

$\S 2^{\circ} \mathrm{ALibrasconstituir-se-áemdisciplinacurricular} \mathrm{optativa} \mathrm{nos} \mathrm{demais}$ cursos de educação superior e na educação profissional, a partir de um ano da publicação deste Decreto (BRASIL, 2005, destaque das autoras)

Desse modo, a partir da indicação de que a oferta da disciplina de Libras inicie a partir de um ano após a publicação do Decreto, é que se pautaram as reflexões e caracterizações deste processo nas IES públicas da Região Centro -Oeste, no âmbito das Universidades Federais de Goiás (UFG), de Mato Grosso (UFMT), de Mato Grosso do Sul (UFTMS), de Grande Dourados (UFGD - MS), de Uberlândia (UFU - MG) e da Universidade de Brasília (UnB).

Este artigo busca compreender como a Política Linguística (Libras) está sendo implementada nas instituições e, para tanto, procurará caracterizar essa oferta a partir dos nomes das disciplinas, de suas cargas horárias, das ementas, dos objetivos, dos cursos em que a disciplina é ministrada, da unidade acadêmica/departamento responsável pela oferta da mesma e dos profissionais que atuam na disciplina, focalizando sua formação e vínculo funcional.

\subsection{A Libras nas universidades federais: fios parecidos, tecidos diver- sificados}

A Libras foi reconhecida em três dos cinco entes federados em que se situam as instituições estudadas, desde a década de 1990 e, nos outros dois, este se deu concomitantemente ao reconhecimento nacional. Portanto, não é uma situação apresentada recentemente. No entanto, em se tratando de uma realidade que demanda a regulamentação e a criação de políticas de indução, este tempo não é considerado muito longo. 
O desdobramento desta ação dos entes federados não apresentou impactos nas IES públicas federais, pois estas não são regidas por eles. Assim, embora tenha sido criada, na realidade estadual, a demanda por profissionais qualificados para atuação na educação básica, acredita-se que estas instituições, considerando seu compromisso público e social, precisariam estar atentas a tais fatos, o que não foi evidenciado nas instituições estudadas.

A partir da publicação do Decreto n. 5.626/05, esta realidade começou a se aproximar dos contextos das IES públicas federais, como também das demais instituições de educação superior públicas e privadas.

A inserção da temática relacionada a escolarização de pessoas surdas, especificamente da Libras, aconteceu, inicialmente, nas IES ${ }^{2}$ que possuíam profissionais pesquisadores na área e, posteriormente, por força determinativa do referido Decreto, que lhes apresentou a demanda. Todavia, é preciso destacar que não houve por parte do Ministério da Educação (MEC), Secretaria de Ensino Superior (SESU), Secretaria de Educação Especial $\left(\mathrm{SEESP}^{3}\right)$, ações indutivas para a criação de condições iniciais reais para atender à situação criada pelo Decreto n. 5.626/05, pois o mesmo não ofereceu alternativas para sua implantação na instituição. Logo, cada IES precisou encontrar caminhos diferenciados para atender à legislação, considerando que não foram designadas vagas para docentes de Libras nestas IES à época.

É importante destacar que as IES estavam tentando se organizar para oferecer as condições mínimas necessárias para seu funcionamento, visto que estavam sob os impactos das ações públicas implementadas na década de 1990, na qual as IES públicas federais passaram por um massivo processo de sucateamento; assim, já estavam enfrentando dificuldades para compor seus quadros existentes e, ainda, tiveram que se reorganizar para abrigar esta nova demanda.

Portanto, demarca-se que, na prática, a responsabilidade pelo cumprimento do Decreto ficou para as IES públicas, deixando o Governo Federal em uma situação mais confortável diante da população surda do País, que efetuava cobranças quanto ao cumprimento legal do decreto. Nesse sentido, as IES, responsabilizadas, eram consideradas por alguns grupos políticos e organizados do País, como instituições morosas, pouco sensíveis às demandas

2 Este estudo trata das IES públicas federais da Região Centro-Oeste.

3 Desde 2011 a SEESP foi substituída pela Diretoria de Políticas de Educação Especial da Secretaria de Educação Continuada, Alfabetização, Diversidade e Inclusão (DPEE/ SECADI). 
sociais das denominadas minorias populacionais brasileiras.

Foi neste contexto que cada IES pública federal foi criando seu desenho dentro das condições encontradas pelos seus grupos gestores.

O Decreto n. 5.626/05, por sua vez, determina a inserção da Libras nos cursos de Licenciatura, mas não apresenta carga horária mínima, habilidades e competências ${ }^{4}$ que precisam ser desenvolvidas nos acadêmicos que a cursarem. Na prática, deixa-lhes a liberdade para compor o componente curricular, o que representa um risco à concretização das expectativas da população surda organizada, que tanto lutou por esta conquista. Cria-se, assim, no imaginário coletivo, a sensação de dever cumprido, de que a partir da concretização do disposto no decreto haverá modificações substanciais na realidade, no entanto, o que de fato ocorre é que as mudanças desejadas ficam restritas e à mercê da sensibilidade de grupos organizados alheios às demandas e necessidades deste grupo específico.

Soma-se a isto, o fato de esta situação compor o quadro atual da existência de um arcabouço legal nacional que abriga as demandas dos grupos minoritários socialmente organizados, proporcionando uma pseudorealidade de incorporação da diferença, dos anseios políticos e sociais, pelo direito à educação, à saúde e à moradia etc. No entanto, tais situações expressas em diferentes formas de manifestação social destes grupos minoritários foram capturadas e ressignificadas pelos discursos utilizados na atualidade, pelo grupo dominante, não sendo traduzidos em realidade.

Portanto, a população surda foi se desmobilizando por acreditar no fato de que a Libras havia sido reconhecida como segunda língua oficial do País, fato este que não ocorreu. Houve somente o seu reconhecimento linguístico, enquanto língua natural da população surda, mas não sua oficialização, pois não foi publicado nenhum decreto lei com mudança no texto constitucional, no qual apresenta a Libras como segunda língua oficial do País, ou seja, o Brasil continua possuindo atualmente apenas a Língua Portuguesa como língua oficial.

Apesar de a realidade ser dinâmica, a sensação decorrente deste fato perdurou por aproximadamente uma década, para então, estes grupos organizados de pessoas Surdas começarem a retomar suas bandeiras de luta e recompor o seu movimento político e social.

4 Terminologia utilizada nas Diretrizes Curriculares Nacionais para se definir o perfil dos egressos, sem apresentar os conteúdos que deverão ser trabalhados nos cursos. 
Neste contexto, é comum a existência de críticas à IES públicas federais quanto ao espaço e à condução do processo de inserção da Libras nos seus currículos, desconsiderando as suas realidades. Entretanto, apesar desses elementos destacados, não é possível dizer que nada foi efetuado, que houveram poucas mudanças reais. Pelo contrário, existem muitas evidências de um trabalho sério e árduo assumido pelas referidas instituições conforme será apresentado a seguir.

A Universidade Federal de Goiás (UFG), além dos dois campi em Goiânia, conta com os campi Jataí, Catalão e Goiás. Neste levantamento sobre a oferta da disciplina Libras no âmbito da UFG, selecionamos os campi Goiânia e o campus Catalão.

Na UFG-Goiânia e no campus de Catalão, a oferta da disciplina de Libras é garantida aos cursos de licenciatura como disciplina obrigatória e aos cursos de bacharelado na condição de optativa - Núcleo Livre. Além disso, ela é ofertada também como Núcleo Livre, modalidade aberta a todos os alunos da UFG.

A Universidade Federal de Mato Grosso (UFTM) tem quatro campi, o de Cuiabá, o do Araguaia, o de Rondonópolis e o de Sinop. A disciplina de Libras, no Campus de Cuiabá acontece com uma carga horária variando entre 60 e 64 horas. Há um diferencial no Curso de Letras nas diversas habilitações (habilitação Língua Portuguesa, Espanhola e Literaturas; Língua Portuguesa, Inglesa e Literaturas; Língua Portuguesa, Francesa e Literaturas; Língua Portuguesa e Literaturas), pois são os únicos cursos em que há duas disciplinas de Libras: Libras I, com 144 horas, e Libras II, com 72 horas (216h no total).

Tem-se como ementa da disciplina Libras I:

Estudo da Língua Brasileira de Sinais (Libras): alfabeto digital, parâmetros linguísticos, relações pronominais e verbais. Estudos discursivos em Libras. A língua em seu funcionamento nos diversos contextos sociais

Busca-se na disciplina Libras II:

Estudos linguísticos da Língua Brasileira de Sinais e estudos gramaticais do Léxico, Sintático, Morfológico, Pragmático, Fonema, Fonologia, Vícios de Linguagem, Polissemia, Metáfora, Comparação e Interfaces da linguística. Processo ensino-aprendizagem do aluno 
surdo frente à Língua Portuguesa. Uso da LIBRAS na prática, em concordância com suas próprias normativas e construção de um educador com competência no uso da LIBRAS como língua materna do seu aluno surdo para o processo do ensino da Língua Portuguesa.

Esta iniciativa no curso de Letras é muito importante, pois coopera com a formação de um professor de Língua Portuguesa capaz de contribuir com o processo de escolarização da população surda, tanto no ensino da Língua Portuguesa como segunda língua, como no ensino da Libras. Esta experiência configura, mesmo que com carga horária irrisória, uma tentativa de formar um professor bilíngue com condições de atuar nos diferentes espaços da educação básica, para a qual o profissional se encontra licenciado, com a população surda e ouvinte do País.

Não foi possível identificar, no estudo documental dos projetos pedagógicos dos cursos da UFMT, disponível on-line, a locação da disciplina nas unidades acadêmicas da instituição. Outro elemento a destacar é que, embora na grande maioria dos cursos a carga horária seja de 60 horas, a ementa não é a mesma:

LIBRAS(60h):Estudo da Língua Brasileira de Sinais (Libras): alfabeto digital, parâmetros linguísticos, relações pronominais e verbais. Estudos discursivos em Libras. A língua em seu funcionamento nos diversos contextos sociais (Curso de Licenciatura em Filosofia da UFMT) (Curso de Letras e Licenciatura em Física).

LIBRAS - LÍNGUA BRASILEIRA DE SINAIS - $60 \mathrm{~h}(0.2 .0)$ EMENTA: Noções básicas de LIBRAS, comunicação entre ouvintes através da LIBRAS; comunicação entre ouvintes e surdos; abordagem sócio antropológicas na Educação Especial; educação e exclusão; comunidade surda; tópicos de estudos científicos em sinais; classificadores; sinais direcionados (Curso de Licenciatura em física da UFMT).

O curso de Licenciatura em Geografia, por sua vez, destina à disciplina de Libras uma carga horária mínima a mais, sendo de 64 horas. Observa-se ainda que sua ementa é muito ampla. 
As políticas de inclusão e exclusão sociais e educacionais. Modelos educacionais na educação de surdos. Aspectos históricos e culturais, linguísticos, educacionais e sociais da surdez. Vocabulário em língua de sinais brasileira. A mediação do conhecimento através do intérprete de língua de sinais. O papel do intérprete de língua de sinais na sala de aula. A definição do que representa o intérprete-pedagógico na educação de surdos (Curso de Licenciatura em Geografia da UFMT).

Esta organização sinaliza para o entendimento de que a UFMT, campus de Cuiabá, não possui uma política única de oferta da disciplina, mas que essa atende à compreensão que cada curso possui sua importância e relevância para o profissional egresso do curso. Nos demais campi (Rondonópolis, Araguaia e Sinop) verificou-se a presença da disciplina de Libras com carga horária de 60 horas. Não se identificou nos documentos on-line a ementa das disciplinas.

A Universidade Federal de Mato Grosso do Sul (UFMS) também possui vários campi: Campo Grande, Aquidauana, Bonito, Chapadão do Sul, Coxim, Naviraí, Nova Andradina, Paranaíba, Ponta Porã, Três Lagoas e Pantanal. São nove professores para atender todos os campi, com a mesma ementa para todos eles:

Noções históricas da inclusão de surdos na sociedade brasileira. Sinais básicos. Aspectos linguísticos da língua brasileira de sinais (libras)), indicando uma política única da instituição para o trato com a temática.

Na Universidade Federal da Grande Dourados (UFGD), a expansão do ensino superior no Estado de Mato Grosso do Sul contou com a ampliação de novos cursos e contratação de professores doutores para a qualificação do ensino e da pesquisa, o que fortaleceu o perfil das licenciaturas e da pós-graduação. Nasce assim, uma Universidade comprometida com o desenvolvimento regional, humano e social e com um perfil mais tecnológico. O primeiro Plano de Desenvolvimento Institucional (PDI-2007-2008) contou com a participação coletiva no debate e criação de estratégias para o desenvolvimento de uma política institucional de inclusão social e educacional, contemplando as políticas linguísticas para os diferentes grupos sociais como os surdos e os povos indígenas. Libras tornou-se disciplina 
obrigatória nas licenciaturas, inclusive no curso de Licenciatura Indígena, e optativa nos demais cursos, como medicina e direito, entre os demais, com carga horária de 72 horas.

Na UFGD 5 , a disciplina Língua Brasileira de Sinais Libras aborda:

Análise dos princípios e leis que enfatizam a inclusão de LIBRAS - Língua Brasileira de Sinais nos cursos de formação docente; apresentação das novas investigações teóricas acerca do bilinguismo, identidades e culturas surdas; as especificidades na construção da linguagem, leitura e produção textual dos educandos surdos; os princípios básicos da língua de sinais, o processo de construção da leitura e escrita de sinais e produção literária em LIBRAS.

A UnB ${ }^{6}$, localizada no Distrito Federal, também possui vários campi avançados fora de sede: Gama, Ceilândia e Planaltina. No campus de Ceilândia e Gama não há cursos de Licenciaturas. No campus de Planaltina é oferecida a Licenciatura Educação do Campo, seu Projeto Pedagógico é de 2009 e não foi identificado, no seu interior, a presença da disciplina

5 Em 2007, a UFGD integra o Programa Especial MEC/UAB/UFSC para a implementação dos cursos de licenciatura específica de Letras/ Libras e Bacharelado/Intérprete, em dezoito universidades públicas brasileiras. Os cursos de licenciatura e bacharelado em Letras/Língua Brasileira de Sinais, do Polo UFGD foi implementado na Faculdade de Educação, sob a coordenação geral da Universidade Federal de Santa Catarina, e proporcionou a formação de 21 profissionais professores de Libras, dos quais 08 são surdos; o bacharelado intérprete de Libras/Língua Portuguesa, formou 18 intérpretes. Os profissionais licenciados eram dos Estados de Mato Grosso do Sul, São Paulo e Paraná. Grande parte dos egressos realizaram concursos públicos para o ensino de Libras e outros de intérpretes de Universidades públicas em nosso Estado. Em 2013, foi criado o curso Letras Libras/Língua Portuguesa na Faculdade de EaD em parceria com a Faculdade de Letras. Em 2015 será criada na Universidade a Pedagogia Bilíngue EaD. Pontua-se que os exames vestibulares da UFGD realizados com o apoio do Laboratório de Acessibilidade e Práticas Inclusivas asseguraram, desde 2009, o vestibular em Libras por meio eletrônico (prova em Libras gravada) com o arquivo e um computador para cada candidato surdo e a prova de redação tem a Língua Portuguesa como segunda língua, além da presença do profissional intérprete em sala.

6 A UnB, a UFG e a UFGD ofertam o curso de graduação Letras-Libras na modalidade a distância, esta última, na Faculdade de EaD em Dourados e no Polo Letras-Libras em Rio Brilhante, atendendo à política do Ministério da Educação de indução de curso para formação de docentes para atender às demandas originárias do Decreto n. 5.626/2005, no qual se determina a inserção da Libras nos cursos de licenciatura. 
Libras. No entanto, no levantamento sobre a oferta da disciplina Libras na Universidade de Brasília on-line, deparou-se com a notícia publicada pela Circular/002/DEG, de 28/1/2009, na qual informa sobre a "inclusão da disciplina optativa de Libras, em conformidade com o Decreto n. 5.626 de 22 de dezembro de 2005, bem como para atender à diligência da DESUPSESU/MEC. A diligência apontava, ainda, a oferta da Libras como disciplina obrigatória para os cursos de Licenciatura.

Por conseguinte, em resposta à referida diligência do MEC, a então decana de ensino de graduação, apresenta a predisposição da instituição em atender ao determinado pela legislação, contudo, esclarece sobre as dificuldades que a instituição possui em modificar a estrutura curricular dos cursos, inserindo um novo componente curricular obrigatório em todos os cursos de licenciatura.

Diante desta realidade, semelhante a vivida pelas demais instituições públicas brasileiras, uma das saídas encontradas, assim como na UFG, foi a oferta da disciplina em lugar de um Núcleo Livre/disciplina optativa já prevista na matriz curricular dos cursos. Essa notícia sugere que a UnB, até 2009, assim, como a UFG, também não ofertavam a disciplina Libras em seus cursos de graduação. Entretanto, foi possível constatar que o Departamento de Linguística, Português e Línguas Clássicas (LIP), um dos três departamentos do Instituto de Letras da UnB, oferta quatro disciplinas de módulo livre na área: Libras Básico, Libras Intermediário I, Libras Intermediário II e Libras Avançado, que, conforme a decana do ensino de graduação, é ofertado desde o ano de 2006.

A UFU, possui 03 campi fora de sede, sendo que apenas em Ituiutaba/ MG, possui cursos de Licenciatura. A política de desenvolvimento da Libras foi a mesma nos campi de Uberlândia e de Ituiutaba. Foi criada pelo Conselho de Graduação, por meio da Resolução n. 13/2008 que "Dispõe sobre a criação das disciplinas Língua Brasileira de Sinais I - Libras Língua Brasileira Sinais II - Libras e dá Outras providências - Processo n. 127/2008" (UFU, 2008), na qual se criava, na instituição, a disciplina Libras, com a seguinte ementa:

Conceito de Libras, Fundamentos históricos da educação de surdos. Legislação específica. Aspectos Linguísticos da Libras.

Apesar de ter sido criada a possibilidade de se ofertar duas disciplinas de Libras para os acadêmicos dos cursos de licenciatura, sendo a Libras I obrigatória e a II, optativa, apenas em 2010 foi ofertada a Libras II, considerando a 
grande demanda para a disciplina Libras I, que é obrigatória, e a relação com a quantidade de professores de Libras existentes na instituição na atualidade.

O levantamento realizado sinaliza que o início da implantação da Libras nas IES públicas federais da Região Centro-Oeste aconteceu entre os anos de 2009 (UFG campus de Catalão, UFMS e UnB) e 2010 (UFMS), UFGD (2007 contratação e concurso público em 2009), e a UFU realizou o primeiro concurso em 2007, e instituiu a Libras nos seus currículos em 2008.

Os professores têm sido contratados, em grande parte, na condição de professores substitutos e os editais trazem como exigência: nível mínimo de graduação em Letras: Libras, ou graduação em outros cursos, como Letras e Pedagogia e com apresentação de certificado Prolibras. Os concursos são abertos, tanto para professores surdos, como para ouvintes, entretanto as vagas têm sido ocupadas prioritariamente pelos professores surdos.

Atualmente a $\mathrm{UFG}^{7}$ conta com cinco ${ }^{8}$ surdos atuando na área. A UFU conta com dez professores, sendo sete surdos e três ouvintes, todos efetivos, com dedicação exclusiva (DE), sendo que um deles, ouvinte, encontra-se lotado no campus de Ituiutaba. Encontra-se em realização um concurso público para preenchimento de duas vagas em Uberlândia e uma em Ituiutaba.

A primeira seleção para professor substituto de Libras na UFGD ocorreu em 2007 e o concurso para efetivação em 2009. A UFGD conta hoje com dezenove cursos de licenciaturas que ofertam, de forma obrigatória, a disciplina Libras, contando com seis professores concursados, todos com mestrado e dedicação exclusiva.

A UFMS possui nove professores, todos ouvintes, efetivos com DE, lotados em Campo Grande, para atender a todos os onze campi da institui-

7 Em agosto de 2010 acontece, na Faculdade de Educação, o primeiro processo seletivo simplificado para professor na área Libras, na condição de professor substituto.

8 Em 2010, ocorre novo processo seletivo simplificado para contratação do professor substituto na área de Libras e são aprovados três candidatos, tendo sido contratados, inicialmente, os dois primeiros classificados em regime de 20 horas. Logo em seguida, o terceiro professor foi contratado para atuar como "professor intérprete", uma vez que esses dois professores aprovados eram surdos. A professora então passa a dividir o papel de intérprete de professores surdos de Libras e de professora da disciplina Libras, tarefa compartilhada com a outra professora contratada em 2009. Desse modo, neste período, o campus fica com quatro professores de Libras, sendo que dois deles atuam em duas frentes, uma na docência da disciplina e outra como intérprete de língua de sinais (TILS). No ano seguinte, este número diminui para três, dois professores surdos e um ouvinte. 
ção. A UnB possui três professores e na UFMT não foi possível identificar o quantitativo de docentes, considerando que não houve retorno dos contatos realizados pelos pesquisadores com a equipe da instituição, sendo coletados apenas dados disponíveis no portal eletrônico da mesma.

Quanto à qualificação dos profissionais atuantes nas instituições, foi possível identificar que a grande maioria possui habilitação em Letras/Libras (80\% dos dados coletados) e muitos possuem duas graduações, sendo uma Pedagogia e a outra Letras. Todos possuem especialização na área da educação especial e inclusão educacional, cinco são mestres em educação, um mestre em física aplicada e um doutor em Linguística. Os professores da UNB, apresentam formação variada, sendo dois em Pedagogia e um em Ciências Biológicas, os três são mestres em linguística pela UnB e cursam doutorado em linguística, também na mesma instituição. Dois deles realizaram o curso Letras-Libras pela UFSC - Polo UnB. Todos têm experiência em docência ou como intérpretes em Libras e um deles, como instrutor de Libras. Dois têm o ProLibras pelo MEC, o primeiro com Tradução e Interpretação (nível superior) e Ensino de Libras (nível superior), e o outro ProLibras e, nesse caso, não é apresentado a distinção, apenas que é para o nível superior e nível médio.

Quanto à responsabilidade pela oferta da disciplina, na UFG, campus de Goiânia ${ }^{9}$, há a oferta da disciplina em duas Faculdades: na Faculdade de Educação e na Faculdade de Letras. Na primeira, para atender aos alunos da própria faculdade e na segunda, para atender aos seus alunos e aos demais cursos da universidade. Em Catalão, a disciplina é ofertada apenas pelo Departamento de Educação. Na UFU a disciplina é lotada na Faculdade de Educação. Com a criação do Curso de Letras com Habilitação em Língua Portuguesa com domínio de Libras, o Instituto de Letras e Linguística (ILEEL) irá ofertar no curso apenas as disciplinas de Libras necessárias que ultrapassem a Libras I e II, lotadas na Faculdade de Educação. Na UFMT

9 Embora a disciplina Libras, UFG Goiânia, seja uma disciplina obrigatória para as Licenciaturas, a sua oferta tem acorrido na condição de núcleo livre até que os Projetos Pedagógicos dos Cursos sejam reformulados, para que esta disciplina seja inserida. Desse modo, no curso de Pedagogia ela é ofertada no $7^{\circ}$ período e ocupa o lugar de um núcleo livre, entretanto todos os alunos devem cursá-la. Além da oferta no curso de Pedagogia, na Faculdade de Educação, ela é ofertada aos alunos do Curso de Psicologia. A disciplina tem como título "Língua Brasileira de Sinais" e uma carga horária de 64 horas semestrais, sendo 4 horas semanais. 
não foi identificada a unidade responsável. Na UFMS os professores estão lotados na Faculdade de Educação. Na UnB a disciplina é ofertada pelo Departamento de Linguística, Língua Portuguesa e Línguas Clássicas (LIP) e há indícios de que a Faculdade de Educação oferece a disciplina; no entanto, não foi possível confirmar oficialmente este dado.

De qualquer forma, esta carga horária utilizadas nas IES investigadas possibilita apenas a introdução à temática, não sendo viabilizadas as condições de aprendizagem da língua. Tal situação possui implicações diretas no processo de escolarização das pessoas surdas na educação básica, principalmente nos anos iniciais, considerando que o processo de alfabetização ocorre na educação infantil e anos iniciais do ensino fundamental, área ocupada por egressos do curso de Pedagogia, que com este perfil não possuem condições elementares para atuar no processo de escolarização deste grupo de pessoas.

Na prática, a inserção da Libras com a carga horária identificada, atua apenas como elemento de sensibilização às necessidades especificadas da população surda usuária da Libras, não correspondendo às expectativas do grupo organizado socialmente destas pessoas quanto à melhoria de suas condições de escolarização.

Conforme pode ser observado, o destaque às questões de aprendizagem da língua são menores, priorizando a inserção dos acadêmicos na realidade de vida das pessoas Surdas, demonstrando suas especificidades e indicando a necessidade de formação continuada na área dos docentes egressos dos cursos de licenciatura atuais.

\subsection{Considerações finais: entre a multiplicidade e/ou a reprodução de estampas}

A oferta da disciplina, no âmbito das universidades públicas investigadas, provocou no seu interior, muitas inquietações e movimentações internas. Houve um desconforto generalizado frente à situação de imposição legal desta demanda, gerando, de certa forma, um novo e recorrente "atentado" à autonomia institucional no tocante à proposição curricular de seus cursos.

$\mathrm{O}$ Estado novamente lança mão de um aparato legal para impor às universidades modificações curriculares originárias de uma demanda social.

Apesar de as instituições terem sofrido com este impacto, considera-se que, caso ele não ocorresse, seria pouco provável que a realidade encontrada 
estaria nas universidades públicas da região Centro-Oeste composta pelo desenho encontrado neste estudo. Mas se se considerar o fato de que - desde a promulgação da Constituição Federal de 1988, e consolidada pela Lei n. 9394/96, Lei de Diretrizes e Bases da Educação Nacional - o Brasil ter optado pela construção de uma educação inclusiva, se na realidade, a formação de professores continua acontecendo até os dias atuais desconsiderando, significativamente, esta questão, à medida que não houve modificações substanciais no processo formativo, pois o fato da inserção de uma ou outra disciplina isolada na formação não garante a mudança de posicionamento e compromisso pedagógico com a aprendizagem e o desenvolvimento de todos.

Assim, apesar do fato descrito, não é possível desconsiderar os efeitos positivos desta medida. Um dos desdobramentos desta situação foi o fato de se propiciar a entrada, neste ambiente altamente elitizado e meritocratizado, de professores surdos, o que, por sua vez, mobilizou a necessidade de novos saberes para o estabelecimento de relações de trabalho no seu interior. A presença de profissionais surdos, gerou a demanda de novos profissionais, tal como a contratação de Intérpretes de Língua Brasileira de Sinais - TILS. Isto pois, para além do espaço de ensino, estes docentes, como os demais, possuem atribuições nas esferas administrativas, de extensão e de pesquisa.

No entanto, o Ministério da Educação, ao determinar que as exigências do Decreto n. 5.626/06 fossem cumpridas, não se preocupou em criar as condições necessárias nas IES para atendê-las. Ou seja, não se criou o cargo de Intérpretes de Libras no quadro das IES, nem tão pouco se disponibilizou vagas para docentes que iriam assumir esta nova demanda induzida. Coube às instituições criarem seus próprios tecidos e estampas para incorporarem estas novas demandas. Na prática, se replicou o modelo vigente de transferência de responsabilidades, tão comum aos processos educacionais. Há sempre um outro a ser responsabilizado pelas situações/ações/políticas/ processos desencadeados.

Assim, ao assumir tal responsabilidade, as instituições, cada uma a sua forma, tentaram equacionar a realidade. Foi se contratando em regime temporário, Intérpretes de Libras, tanto para atender aos docentes nas atividades de pesquisa, extensão e administração, como para atender à discentes surdos que foram ingressando nas IES com o decorrer do tempo, com a implementação ou não do Curso Letras-Libras, na modalidade presencial e/ou a distância. 
Portanto, destaca-se que as primeiras iniciativas de implantação da disciplina Libras e sua oferta têm sido realizadas a partir do esforço de pessoas e Unidades Acadêmicas/Departamentos envolvidos com a educação de surdos e o ensino de Libras. Embora haja alguns professores efetivos para os cursos de Letras-Libras, induzidos pelo MEC/SESU/SECADI, o que se constata, segundo uma das professoras do curso de Letras-Libras, é que a oferta vem acontecendo "sem que sejam criadas as condições viáveis para isso, pois não se abrem vagas para professores de Libras efetivos em número suficiente para atender às demandas." As modificações neste processo só vieram a ocorrer com o Programa Viver Sem Limites do Governo Federal, que procurou induzir a criação de cursos de formação de professores para os processos de escolarização da população surda a partir de 2013. Estes profissionais ainda estão chegando às IES que atenderam ao processo de indução, portanto, a realidade apresentada não considera estes profissionais.

É notório, portanto, neste processo, que há que se considerar e explorar com a população surda e ouvinte muitos outros aspectos, como:

a) a capacidade de utilização da Libras em contextos escolares e não escolares, como instrumento de comunicação e ensino, sinalizada nas ementas e objetivos da disciplina, demandaria uma formação mais sólida, uma vez que não se estabelece diálogo com sinais isolados de cumprimento, numerais, cores, dia, noite, estados físicos da natureza, etc. Neste caso, cria-se no imaginário dos licenciados, que eles terão condições para estabelecer o mínimo de situações comunicativas com seus futuros alunos surdos, mas na realidade, isto não seria possível, pois a língua é viva, demanda contato com seus usuários por um tempo prolongado, o que uma disciplina não tem condições de oferecer. Por outro lado, a mesma questão se coloca em ambientes não escolares, que irão demandar o conhecimento de um vocabulário mais ampliado, que ultrapasse, inclusive, aquele comum ao ambiente educacional. b) a utilização de metodologias de ensino destinadas à educação de alunos surdos, tendo a Libras como elemento de comunicação, ensino e aprendizagem. Este objetivo estará extremamente prejudicado, ao se observar que suas intenções demandariam a carga horária total da disciplina, aliada à presença de um professor de Libras com formação adequada para pensar as questões relacionadas ao ensino. Não se trata de saber e/ou ser usuário da Libras, mas um conhecedor de metodologias de ensino e de educação 
de surdos. Situações que, no futuro, poderão ocorrer, mas na atualidade, ainda há muito a caminhar. Paralelo a tal situação, também existe, nos processos de ensino de Libras nas IES, o fato de os professores de Libras, principalmente os surdos, realizarem seu trabalho desconsiderando o fato de que eles estão ensinando Libras a ouvintes, utilizando de metodologias, muitas vezes, inadequadas para o ensino de segunda língua, contexto para o qual eles dizem se sentirem preparados.

c) o fato de a disciplina de Libras possuir uma natureza diferente e isto ser desconsiderado pelas IES na organização das turmas, pois trata-se de um componente de natureza visual-gestual, do qual demanda um número menor de acadêmicos por turmas. No levantamento realizado para elaboração deste texto, identificou-se que as turmas variam de 30 a 60 estudantes, de acordo com as demandas de cada IE e a relação professor $\mathrm{x}$ estudantes.

No entanto, apesar de aparentemente as dificuldades apresentadas estarem vinculadas apenas ao campo administrativo, no tocante à criação do componente curricular nos projetos pedagógicos dos cursos de licenciatura e a destinação de vagas de docentes para compor os cargos necessários à garantia da oferta destes componentes curriculares, existem outras demandas mais profundas que precisam ser perseguidas, tais como aquelas relacionadas às mudanças de atitudes e posturas.

Portanto, é possível depreender que neste universo há muito a ser modificado, principalmente a superação dos verbos respeitar, tolerar, aceitar, substituindo-os por verbos como reconhecer, compreender e estabelecer condições de e/ou para, de natureza implicativa, logo, que requerem envolvimento, tomada de decisão, compromisso com a questão estudada, fatores estes que solicitam do professor habilidade para promover discussões teóricas fundamentadas, politizadas e bem articuladas com as demandas reais da educação inclusiva e bilíngue na sociedade brasileira.

Contudo, considerando que as condições de oferta da disciplina sejam ainda precárias, seja em relação à sua inserção nas matrizes curriculares dos cursos ou em relação às condições de trabalho dos professores, o processo de instauração de mudanças, na realidade, já se iniciou. Agora não há como ter controle absoluto dos resultados.

No que se refere às exigências de formação dos docentes para assumirem a disciplina de Libras nas IES, foi possível constatar que não há uma definição da graduação pelas instituições investigadas, geralmente são professores que 
cursaram licenciatura, principalmente em Pedagogia e Letras. Em relação à exigência de proficiência em Libras, também não há definição de que ela aconteça na forma de ensino, podendo acontecer por meio de atividades de extensão e/ou de cursos de aperfeiçoamento e aprofundamento profissional, sendo certificadas pelo exame de proficiência em Libras, realizado por IES públicas federais autorizadas pelo MEC e, em alguns casos, se aceita para o exercício profissional com o ensino de Libras, a certificação oferecida por órgão vinculado à Secretaria Estadual de Educação.

$\mathrm{Na} \mathrm{UnB}$, todos os professores têm mestrado e, em relação às demais universidades, o mesmo ocorre apenas em relação aos professores efetivos da UFG-Goiânia, sendo que os outros professores das demais instituições têm apenas graduação e/ou especialização. Observamos ainda que os professores de Libras geralmente estiveram, antes do ingresso nas universidades, vinculados à educação especial ou à educação de surdos, ou mesmo foram professores surdos na rede pública de educação básica

Destaca-se que a presença de profissionais concursados, efetivos, oferece garantia de estruturação de um trabalho mais sólido, duradouro, com formação de equipe de trabalho com possibilidade de inserção no ensino, na pesquisa e na extensão, consolidando um ciclo de atividades na área.

Por conseguinte, é possível registrar que houve uma expansão significativa de profissionais de Libras nas IES investigadas, no entanto, não é possível afirmar que a disciplina incorpora os desejos da comunidade surda, expresso pelas universidades públicas da região Centro-oeste, mas que para além desta assunção, precisa ser dimensionada a sua amplitude em relação ao tempo/meio disponível, naquele momento histórico, para sua concretização, ou seja, não se trata de utopia, mas de processo, de situação de construção, no qual todos se encontram imersos. O tecido foi definido, agora é pintar a estampa e definir as peças a serem confeccionadas no futuro.

\section{Referências}

BRASIL. Decreto ${ }^{\circ} 5.626$ de 22 de dezembro de 2005. Regulamenta a Lei $\mathrm{n}^{\circ} 10.436$, de 24 de abril de 2002, que dispõe sobre a Língua Brasileira de Sinais - Libras, e o art. 18 da Lei no 10.098, de 19 de dezembro de 2000. Distrito Federal, Brasília. Disponível em: $<$ http://www.planalto.gov.br/ccivil_03/_ato2004-2006/2005/decreto/d5626.htm>. Acesso em: 22 Set. 2014. 
BRASIL. Lei $n^{\circ} 10.436$, de 24 de abril de 2002. Dispõe sobre a Língua Brasileira de Sinais - Libras e dá outras providências. Disponível em: $<$ http://www. planalto.gov.br/ccivil_03/leis/2002/L10436.htm>. Acesso em: 22 Set. 2014.

BRASÍLIA. Distrito Federal, Lei $n^{\circ} 2.532$, de 2 de março de 2000. Determina a habilitação de servidores públicos do Distrito Federal para interpretação da expressão gestual utilizada por portadores de necessidades especiais, DF. Disponível em: $<\mathrm{http}$ //www.tc.df.gov.br/SINJ/TextoArquivoNorma.aspx?id_file=71d70b5b-7afe-3af4-b2d2-c010e0c51a77>. Acesso em: 22 Set. 2014.

BRASÍLIA. Distrito Federal. Lei $n^{\circ}$ 2.089, de 29 de setembro de 1998. Institui a obrigatoriedade de inserção, nas peças publicitarias produzidas para veiculação em emissoras de televisão, da interpretação da mensagem em legenda e na Língua Brasileira de sinais, DF. Disponível em: $<\mathrm{http}: / /$ www.tc.df.gov.br/SINJ/TextoArquivoNorma.aspx?id_file=e2540728-3f2b3 fc5-94e9-059fd401a626>. Acesso em: 22 Set. 2014.

BRASÍLIA. Lei $n^{\circ} 2.272$ de 31 de dezembro de 1999. Dispõe sobre a prestação de serviço suplementar ao serviço telefônico público para pessoas portadoras de necessidade especial tipo auditiva. Disponível em: <www.tc.df.gov.br/SINJ/ Arquivo.ashx?id_norma_consolidado=50231>. Acesso em: 20 Set. 2014.

BRASÍLIA. Universidade de Brasília. Circular/002/DEG, de 28/1/2009. Informa da inclusão da disciplina optativa de Libras, em conformidade com o Decreto N.5626, de 22/12/2005, bem como para atender à diligência da DESUP-SESU/ MEC. Disponível em: $<$ http://www.unb.br/administracao/decanatos/deg/downloads/circ_resol/subtitulos/libras.pdf>. Acesso em: 10 Jan. 2014.

BRITO, Fábio Bezerra de. O movimento social surdo e a campanha pela oficialização da língua brasileira de sinais. 2013. 274f. Tese (Doutorado em Educação) - Faculdade de Educação, Universidade de São Paulo, São Paulo, 2013.

CAMPO GRANDE. Lei ${ }^{\circ}$ 2.997, de 10 de novembro de 1993. Dispõe sobre o reconhecimento oficial, no município de Campo Grande-MS, como meio de comunicação objetiva e de uso corrente, a linguagem gestual codificada na língua brasileira de sinais Libras. Disponível em: $<$ http://cm-campo-grande. jusbrasil.com.br/legislacao/252126/lei-2997-93>. Acesso em: 22 Set. 2014. 
GOIÁS. Lei ${ }^{\circ} 12.081$, de 30 de agosto de 1993. Reconhece oficialmente no Estado de Goiás, como meio de comunicação objetiva e de uso corrente, a linguagem gestual codificada na Língua Brasileira de Sinais - LIBRAS. Disponível em: <http://www.gabinetecivil.go.gov.br/pagina_leis.php?id=3227>. Acesso em: 20 Set. 2014.

MATO GROSSO DO SUL. Lei n ${ }^{\circ} 2.469 / 02$

MATO GROSSO DO SUL. Lei $n^{0} 7.831 / 02$

MATO GROSSO DO SUL. Lei n ${ }^{\circ} 7.835 / 02$

MATO GROSSO DO SUL. Secretaria Municipal de Educação de Campo Grande. Resolução n ${ }^{\circ}$ 31/00

MATO GROSSO DO SUL. Secretaria Estadual de Educação. Lei n ${ }^{\circ}$ 1.693/96

MINAS GERAIS. Lei ${ }^{\circ} 10.379$, de 10 de janeiro de 1991. Reconhece oficialmente, no Estado de Minas Gerais, como meio de comunicação objetiva e de uso corrente, a linguagem gestual codificada na Língua Brasileira de Sinais - LIBRAS. Disponível em: <http://crv.educacao.mg.gov.br/banco_objetos_crv/\%7B90AA857A-F928-4861-A7F3-44076BD2BB60\%7D_LEI\%20 10379,\%20de\%2010\%20DE\%20JANEIRO\%20DE\%201991.pdf $>$. Acesso em: 10 Set. 2014.

MINAS GERAIS. Lei n ${ }^{\circ} 20.828 / 13$.

MINAS GERAIS. Lei ${ }^{\circ} 7.762 / 00$.

UNIVERSIDADE FEDERALDE UBERLÂNDIA. Resolução CONGRAD/ $U F U n^{\circ} 13$, de 29 de dezembro de 2008. Dispõe sobre a criação das disciplinas Língua Brasileira de Sinais - Libras I e Língua Brasileira de Sinais - Libras II, e dá outras providências. Disponível em: <http://www.reitoria. ufu.br/Resolucoes/ata CONGRAD-2008-13.pdf>. Acesso em: 20 set. 2014.

Data de registro: $13 / 04 / 2015$

Data de aceite: 26/08/2015 